\title{
Neural mobilization for brachial neuralgia among Cellulo-Teno Periosteo Myalgic Syndrome (CTPMS) patients
}

\begin{abstract}
Neural Mobilization is an effective tool in the management of the neural sensitivity disorders. This can be used to treat the brachial neuralgia among Cellulo Teno Periosteal Myalgic Syndrome (CTPMS) patients. The specific objective of the study was to evaluate the efficacy of neural mobilization in brachial neuralgia and role neural mobilization in improving the cervical ROM is also evaluated. A total of twenty samples participated in the study. Reduction in pain intensity was significant in both the groups. Gaining the mechanical connection of the nervous system may also assist patients in accepting why movement of body parts distant from the site of symptoms may be used as a treatment approach to mobilize neural tissues. Neural tissue mobilization techniques are passive or active movements that focus on restoring the ability of the nervous system to tolerate the normal compressive, friction, and tensile forces associated with daily and sport activities.
\end{abstract}

Question: Role of Nerve Mobilization in Brachial Neuralgia among Cellulo Teno Periosteal Myalgic Syndrome Patients.

Design: Pre Post Experimental Study design.

Participants: Brachial neuralgia with CTPMS who have decreased cervical rotation ROM in the Age group 25-40 includes both sexes (male and female) predominantly White collar occupation.

Intervention: Nerve mobilization technique for total brachial plexus ULTT1 was used as the neural mobilization tool, intermittent cervical traction \& Interferential therapy.

Outcome measures: Pain was measured using visual analogue scale \& Cervical rotation Range of motion was measured by using the inch tape method.

Results \& conclusion: The result concluded that neural mobilization is more effective than (IFT) interferential therapy while combined with (ICT) intermittent cervical traction in the re-abilitation of brachial neuralgia among CTPMS patients and hence it can be combined with intermittent cervical traction to reduce pain and improve cervical rotation ROM for brachial neuralgia patients.

Keywords: Cellulo Teno Periosteal Myalgic Syndrome (CTPMS), Brachial Neuralgia, Nerve Mobilization
Volume 2 Issue I - 2015

\author{
Bhojan Kannabiran,' Suresh Kumar,' \\ Ramasamy Nagarani' \\ 'RVS College of Physiotherapy, India \\ ${ }^{2}$ Yasodha Physiotherapy center, India
}

Correspondence: Bhojan Kannabiran, Physiotherapy Department, RVS College of Physiotherapy, Coimbatore, India, Tel 919894151846, Email physiokanna@gmail.com

Received: October 20, 2014 | Published: January 23, 2015
Abbreviations: CTPMS, Cellulo Teno Periosteo Myalgic Syndrome; ICT, Intermittent Cervical Traction; IFT, Interferential Therapy

\section{Introduction}

Cellulo Teno Perisoteio Myalgic Syndrome (CTPMS) mentions to collective symptoms that probably due to aging \& degeneration in the spine at the vertebra of the neck. ${ }^{1,2}$ With aging the vertebrae gradually form osteophytes, and their intervertebral disks slowly contract. These deviations alter the arrangement and steadiness of the spine. They produce complications related to compression over the vertebral column andconnected interface including the nerves and blood vessels. CTPMS affects both sexes where men are more prone at an earlier age than women are. CTPMS can also, result in crushing of nearby nerves or the spinal cord resulting in symptoms such as, Sensory symptoms from arms such as pins and needles and Lack of sensitivity in hands. A disorder concomitant with irritation of the brachial plexus. Brachial neuralgia usually denotes to pain connected with brachial plexus irritation due to any pathology disturbing the neural interface. Brachial neuralgia is antagonizing neural disorder which discharges predominant sensory symptoms like pain \& occasionally motor symptoms to the arm in the specific path of the involved nerve. ${ }^{1,3}$ The pain pattern in brachial neuralgia is continuous, piercing, intense, scorching, shooting, radiating, and bothersome leading to in capacitation and sometimes it comes and goes just like explosions one scared of it. The cervical vertebrae C5, C6, C7 are the more prone regions for degeneration or resistance loss with actions consequently leading to brachial plexus of these roots frequently get inflamed. ${ }^{4}$ Neural mobilization is an advanced therapeutic tool which implicates conservative treatment on correction of interfaces of nerves, numerous neural mobilizing skills and patient education methods. Neural mobilization provides appreciative and managing strategies for common syndromes such as nerve root disorders, carpal tunnel disorders, spinal pain and heel fasciitis. Neural mobilization is a technique of traditional treatment of ailments of neural tissue. ${ }^{5}$ The validation for using neural mobilization in the treatment of musculoskeletal conditions is based on research which plug to a high value of neural mobilization procedures. ${ }^{6}$ 
Fundamentally the whole neural system is an unbroken structure and it travels and glides in the body as we keep moving and the movement is related to intricate functional physiology such as blood flow to neurons. This association is quite vivid and it is easy to visualize that fluid such as blood in the nerve cot, a shrinking scar, swelling around the nerve or a nerve having tocope with arthritic changes. ${ }^{4,5,7}$ Accomplishing the mechanical connection of the neural system may also contribute patients in tolerating why active or passive movement of body fragments far from the site of symptoms may be used as a treatment approach to mobilize neural tissues. Neural tissue flossing techniques are osteokinematic movements that concentrate on reestablishing the ability of the neural system to tolerate the normal neural interface forces, resistance, and stretchy powers associated with daily and sporting movements. These healing movements should be having a constructive impact on signs by cultivating intra-neural circulation, axoplasmic flow, neural connective tissue viscoelasticity, and by decreasing the threshold of sensitiveness in brachial neuralgia, also should reduce annoying fear of movement, research studies reconnoitering neural tissue mobilization techniques were commonly utilizing changes in patient's reporting themselves on pain and the severity of participation restriction leading to disability.

\section{Aim and need of the study}

Brachial neuralgia is coined when the patients with symptoms of radiating pain the upper limb and it is a most common presentation seen in day to day practice coexisting with CTPMS. It is usually treated by electro therapeutics like IFT \& TENS..$^{8-10}$ These modalities comforted \& were working on symptoms symptomatically but were not successful in re-establishing purpose like in terms of correction of the neural interface responsible for the irritation. Neural mobilization and IFT are proficient and are really worth in treatment of brachial neuralgia among CTPMS. ${ }^{6,11}$ Hence there is a necessity to explore the success \& compliance of nerve mobilization technique in getting rid of pain \& re-establishing functional (ROM) which is the inevitable concern in the management of CTPMS patients with brachial neuralgia.

\section{Materials and methods}

\section{Study design}

The study is experimental, comparative.

\section{Settings}

The study was conducted in RVS hospital, sulur, Coimbatore

Yasodha physiotherapy centre, H.S hospital, Coimbatore

Vinayaga physiotherapy centre, V.G medical centre, Coimbatore

\section{Inclusion criteria}

Cellulo Teno Periosteo Myalgic Syndrome (CTPMS), with brachial neuralgia

Reduced cervical rotation ROM

Age band 25-40

Both male and female subjects

Executive's in White collar occupation.

\section{Exclusion criteria}

Neural fatigue- myopathies

\section{Oversensitive}

Extruded Inter vertebral disc

Autonomic Involvement, dizziness

Congenital cranial settling pathologies of cervical spine

\section{Sample population}

Out of 236 CTPMS patients 20 subjects who fulfill the selection criteria were selected and randomly allotted 10 in respective group cluster. Sample selection is by Random sampling technique.

\section{Variables used in the Study}

\section{Independent variables}

Nerve mobilization technique

Intermittent cervical traction

Interferential therapy

Dependent variable

Pain

Cervical rotation Range of motion.

\section{Method}

Twenty samples selected from the population divided into two equal groups.

The procedure was explained to the subjects.

The groups underwent a pre-test score of pain intensity measure by visual analogue scale and cervical rotation range of motion with measuring tape was done.

Group I was treated with intermittent cervical traction and IFT.

Group II were treated with intermittent cervical traction and neural mobilization for 2 weeks.

Both the groups were treated and after 2 weeks' time measure of pain by visual analogue scale and cervical rotation range of motion measure were done with measuring tape.

\section{Measuring Tool}

\section{Pain scale (Visual VAS analogue scale)}

Pain (VAS) scale contains of $10 \mathrm{~cm}$ horizontal line with 2 end points, categorized no pain and most horrible pain correspondingly. The patient is invited to place a spot on the $10 \mathrm{~cm}$ line to know his pain intensity at that actual time (presently feeling). The space in $\mathrm{cm}$ from the lesser end of VAS to the patients mark is used as anarithmetic index of the severity of pain. Cervical rotation is in the range of motion with measuring tape.

Position of patient: High sitting.

Therapist position: In forward-facing of the patient.

Measurement: (Tape measure) a direct measure is obtained through the use of a tape measure for cervical spine movement. Start position: The patient is s on a chair sitting with a back support. The head and neck are in the functionally anatomical position.

End position: The patient rotates the head (without flexing or extending) to the limit of rotation. 
Measurement: A tape measure is used to quantify the distance between the tip of the chin and the acromion process. A measure is taken in the anatomical position and at the limit of motion of rotation.

\section{Comprehensive description of Modalities used in the study}

A routine application ICT was applied to patients with a traction pull approximately $1 / 10$ of the body weight. IFT was applied with base spectrum settings of $80-110 \mathrm{~Hz}$. Nerve mobilization was done using the ULTT1 tool which addresses the total brachial plexus tension as a routine for the subjects in the experimental group II.

\section{Results \& discussion}

\section{Results}

A fair study comparative basically was done to find out the practicality of neural mobilization for the neural symptoms grossly termed as brachial neuralgia among CTPMS patients. Twenty (20) CTPMS patients with brachial neuralgia whowere referred from general practioners \& ortho \& neuro consultants for physical therapy management those willing to participate in the study and were indiscriminately divided into 2 groups, group-I and group-II, each having 10 subjects. (ICT) intermittent cervical traction and (IFT) interferential therapy for a time period of two weeks was used to treat Group-1 subjects. Those in the Group-II were treated with (ICT) intermittent cervical traction and neural mobilization for time period of 2 weeks. There was a noticeable mean difference value that showed decrease in pain which was 2.5 for group-I (Figure 1A) and for 3.2 for group-II (Figure 1B). Group-1 resulted in a calculated t value of 14.97 (Table 1A) and that of group-II was 29 (Table 2A) which were significant at 0.05 level of significance which implies that there is significant reduction of pain in both groups statistically (Figure 2A $\& 2 \mathrm{~B}$ ). The independent ' $\mathrm{t}$ ' test done between the groups was 3.603 which is greater than the ' $\mathrm{t}$ ' value (1.734) (Table $3 \mathrm{~A}$ ) which again is statistically significant. Pain reduction is remarkable with neural mobilization. The improvement in range of motion value was 2.4 for group I (Table 1B) and for group-II were 3.2 (Table 2B).

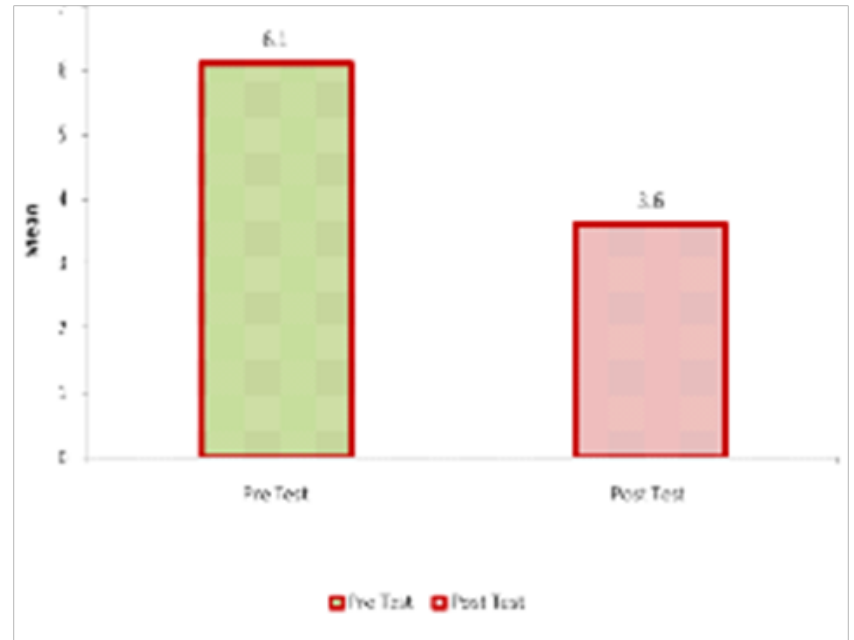

Figure IA Mean pain score for group-I.

The student paired ' $t$ ' test was 14.72 group1 and that of group-II is 23.988. Clearly indicating that both the groups have appreciable improvement post intervention where the group-II is more significant than the other group. Independent ' $t$ ' test was for range of motion resulted in a calculated value (1.647) is less than the ' $t$ ' (Table 3B) value (1.734) at 0.05 level for range of motion. Hence cervical range of motion is statistically more significant (Figure 3A \& 3B).

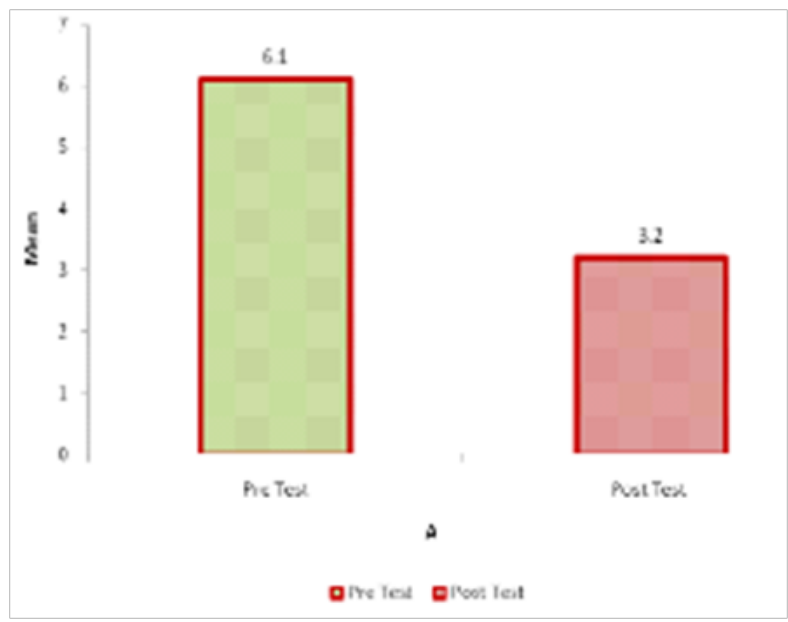

Figure IB Mean pain score for group-II.

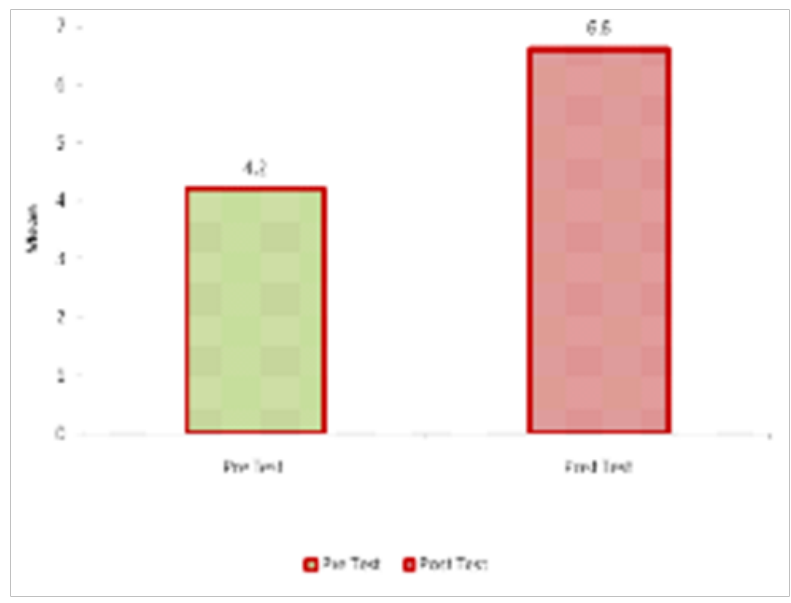

Figure 2A Mean pain score for group-II.

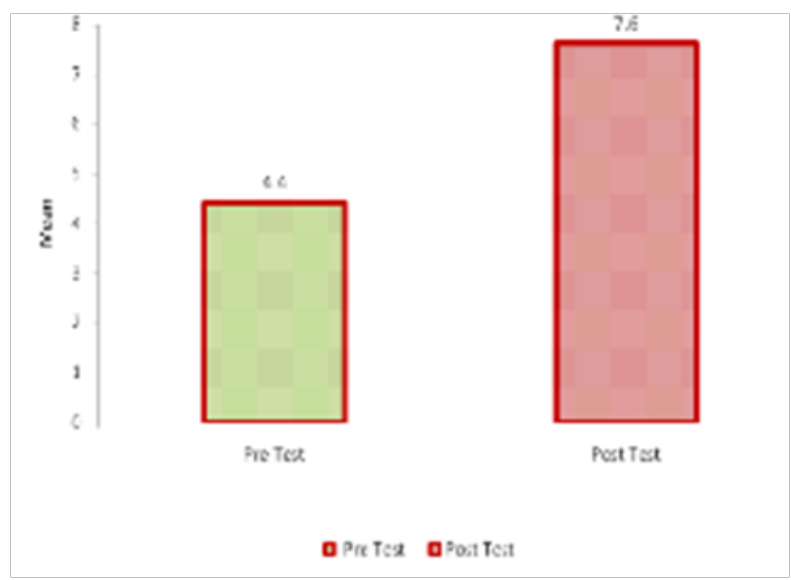

Figure 2B Mean cervical rotation ROM for group-II.

The group-II shows astounding improvement in range of motion after neural mobilization there is an appreciable statistical significant difference in the rehabilitation of brachial neuralgia in between group- 
1(ICT \& IFT) and group-II (ICT \& Nerve Mobilization) among CTPMS patients as there was a significance when compare to the table value.

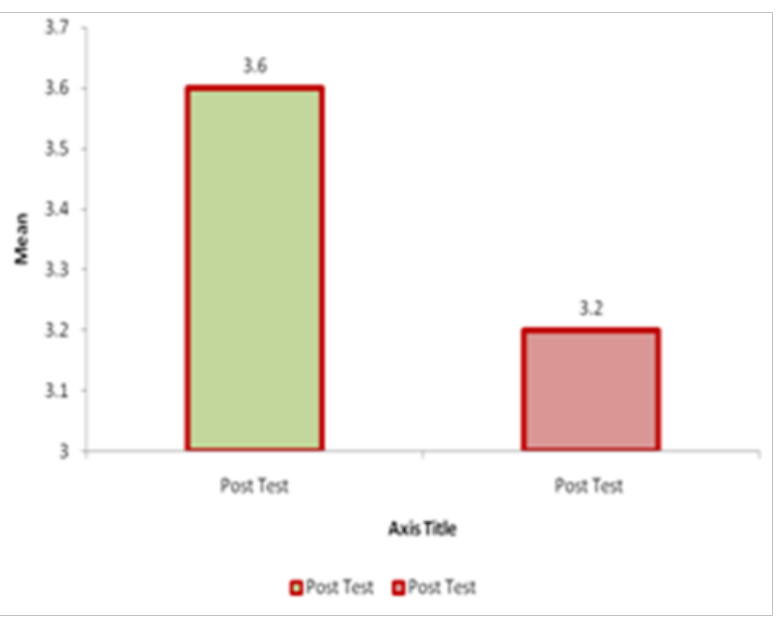

Figure 3A Mean pain score b/w group-l and group-ll.

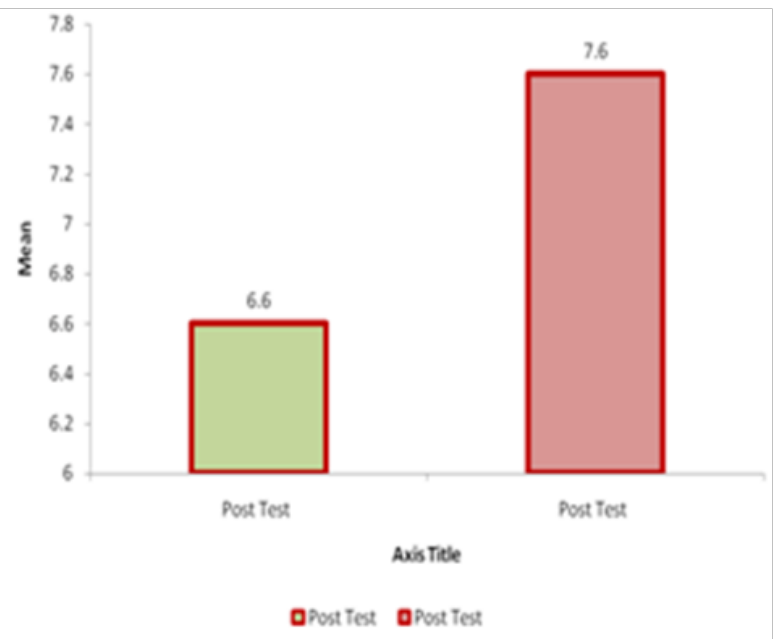

Figure 3A Mean pain score b/w group-I and group-II.

Table IA Mean pain score for group-I before and after treatment (ICT \& IFT) and its statistical significance (paired ' $t$ ' test)

\begin{tabular}{|c|c|c|c|c|}
\hline Intervention & Mean & $\begin{array}{l}\text { Mean } \\
\text { Difference }\end{array}$ & $\begin{array}{l}\text { Standard } \\
\text { Deviation }\end{array}$ & $\begin{array}{l}\text { Paired 't' } \\
\text { Value }\end{array}$ \\
\hline Before & 6.1 & \multirow[b]{2}{*}{2.5} & \multirow[b]{2}{*}{0.53} & \multirow[b]{2}{*}{$14.97^{*}$} \\
\hline After & 3.6 & & & \\
\hline
\end{tabular}

The calculated ' $t$ ' value (I4.97) is greater than the ' $t$ ' table value (I.883) hence there is statistically significant improvement in group-I following intervention. $\mathrm{df}=$ degree of freedom $=9$

$P \leq 0.05$ (the probability of observing value of ' $t$ ' greater than I.883 at 9 degree of freedom is 0.05 or $5 \%$ ).

\section{Discussion}

Reduction in pain intensity was significant in both the groups (intermittent cervical traction with interferential therapy and intermittent cervical traction with neural mobilization). Pain relief in both the group occurred due to correction of positional fault and reduced stress in neck structures. The primary objective in neuromobilization is to improve neuromechanical function through mobilization of peripheral nerves, spinal roots, spinal meninges and the perineural connective tissue. ${ }^{5}$ Restricted cervical rotation range of motion is one of the causes for brachial neuralgia among CTPMS patients. ${ }^{4}$ In circumstances of pain prevention, the patient fears pain and evades movements that provoke it. Prevention can become extreme, such that the patient may never actually perform movements from which the physical problem would benefit and this may impact on ill health. Fear of the pain as such can occur but the notion that injury and pain are closely linked is also frequently a problem.

Table IB Mean cervical rotation ROM score for group-I (ICT\&IFT) and its statistical significance

\begin{tabular}{lllll}
\hline Intervention & Mean & $\begin{array}{l}\text { Mean } \\
\text { Difference }\end{array}$ & $\begin{array}{l}\text { Standard } \\
\text { Deviation }\end{array}$ & $\begin{array}{l}\text { Paired 't' } \\
\text { Value }\end{array}$ \\
\hline Before & 4.2 & 2.4 & 0.516 & $14.72^{*}$ \\
\hline
\end{tabular}

*Significant

The calculated ' $\mathrm{t}$ ' value for group-I (14.72) is greater than the ' $\mathrm{t}$ ' table value 1.833 at 9 degrees of freedom which indicates statistically significant improvement in group-l after treatment.

Table 2A Mean pain score for group-II before and after intervention (ICT \& Neural Mobilization) and its statistical significance (paired ' $t$ ' test)

\begin{tabular}{lllll}
\hline Intervention & Mean & $\begin{array}{l}\text { Mean } \\
\text { Difference }\end{array}$ & $\begin{array}{l}\text { Standard } \\
\text { Deviation }\end{array}$ & $\begin{array}{l}\text { Paired 't' } \\
\text { Value }\end{array}$ \\
\hline Before & 6.1 & 2.9 & 0.316 & $29 *$ \\
After & 3.2 & & & \\
\hline
\end{tabular}

*Significant

The calculated ' $t$ ' value (29) is greater than the ' $t$ ' table value (I.833) which shows statistically significance of improvement in group-II after intervention.

Table 2B Mean cervical rotation range of motion scores for group-ll before and after intervention (ICT \& Neural Mobilization)

\begin{tabular}{lllll}
\hline Intervention & Mean & $\begin{array}{l}\text { Mean } \\
\text { Difference }\end{array}$ & $\begin{array}{l}\text { Standard } \\
\text { Deviation }\end{array}$ & $\begin{array}{l}\text { Paired ' } t \text { ' } \\
\text { Value }\end{array}$ \\
\hline Before & 4.4 & 3.2 & 0.422 & $23.988^{*}$ \\
After & 7.6 & & & \\
\hline
\end{tabular}

*Significant

The calculated ' $t$ ' value (23.988) is greater than the ' $t$ ' table value (I.833) showing high significance of improvement statistically for group-II after intervention.

Table 3A Mean pain score for group-I (ICT \& IFT) and group-II (ICT \& Neural Mobilization) after intervention and their statistical significance (unpaired ' $t$ ' test)

\begin{tabular}{llllll}
\hline Group-I & & Group-II & $\begin{array}{l}\text { Mean } \\
\text { Difference }\end{array}$ & $\begin{array}{l}\text { Unpaired } \\
\text { 't' Test }\end{array}$ \\
\cline { 1 - 4 } Mean & SD & Mean & SD & & \\
\cline { 1 - 4 } 3.6 & 0.699 & 3.2 & 0.789 & & $3.603^{*}$ \\
\hline
\end{tabular}

*Significant

The calculated' value (3.603) is greater than the ' $t$ ' table value (I.734) which indicates statistical significance between group-I and group-II (after intervention).

$\mathrm{df}=$ degree of freedom $=18$

$\mathrm{P} \leq 0.05$ (the probability of observing value of ' $\mathrm{t}$ ' greater than $\mathrm{I} .734$ at I 8 degree of freedom is 0.05 or $5 \%)$. 
Table 3B Mean cervical rotation range of motion score for both group-I (ICT \& IFT) and group-II (ICT \& Neural Mobilization) after treatment

\begin{tabular}{lllllll}
\hline Group-I & \multicolumn{3}{l}{ Group-II } & $\begin{array}{l}\text { Mean } \\
\text { Difference }\end{array}$ & $\begin{array}{l}\text { Unpaired ' } t \text { '' } \\
\text { Test }\end{array}$ \\
\cline { 1 - 4 } Mean & SD & Mean & SD & & I & $1.647^{*}$ \\
\cline { 1 - 4 } 6.6 & 1.476 & 7.6 & 1.229 & & \\
\hline
\end{tabular}

*Significant

The calculated ' $t$ ' value $(I .647)$ is greater than the ' $t$ ' table value (I.734) which indicates statistical significance between group-I and group-II (after intervention)

$\mathrm{df}=$ degree of freedom $=18$

$\mathrm{P} \leq 0.05$ (the probability of observing value of ' $\mathrm{t}$ ' greater than $\mathrm{I} .734$ at I 8 degree of freedom is 0.05 or $5 \%$ ).

When pain is experienced recurrently, the consequence in the patient's mind is that a body structure has been re-injured, therefore decides not to repeat the provoking movements. ${ }^{12} \mathrm{~A}$ cycle of deconditioning of musculoskeletal tissues is created. The problem is then maintained by fear and avoidance of pain. Pain avoidance can be treated as an accustomed response by observing the patient's fear, protective muscular responses and pain during relevant neural sensitivity testing and helping the patient to gain control over them. Instruction on what the treatment will be and the likely outcome are also important. The use of (ICT) intermittent cervical traction with (IFT) interferential therapy and intermittent cervical traction with neural mobilization enabled the escalated increase in cervical rotation range of motion and remarkable decrease in pain. ${ }^{8-10}$ Nerve mobilization tends to focus on one part of the pain and disability problem, namely the structures assumed to be at fault. This is a tissue based afferent approach which does not take into account many other types of events that cause pain and ill health. In reality, the psychosomatic and somatic are always parts of the same problem. ${ }^{12}$ They are linked by the nervous system and each can be used to impact each other. The fact is that nerve mobilization operates on all levels of the healing process. Defensive muscular action from the upper trapezius, brachialis, and biceps adds to strugglecome across by the clinician during Nervous system mobilization is suitable for signs \& symptoms whose roots may be compromised biomechanically or response of inflammation, these two situation will regularly co-occur, although one will dominate \& select treatment regime. ${ }^{13-24}$ Normal movement will optimize the axonal transport systems. Normalization of interface will affect the axoplasmic flow. There was improvement which was statistically significant in cervical rotation range of motion and reduction in pain on the last day of treatment in both the experimental groups, but group II (ICT \& Neural Mobilization) showed more appreciable statistical Significance.

\section{Conclusion}

There was no Difference in base line between groups in the study sample. Group-II revealed more remarkable progress than group-I after intervention. Re-habilitation of brachial neuralgia among CTPMS patients, neural mobilization is far better in effectiveness than (IFT) interferential therapy while combined with (ICT) intermittent cervical traction. In order to decrease pain and progress cervical rotation ROM for CTPMS with brachial neuralgia patients can be subjected to neural mobilization combined with intermittent cervical traction.

\section{References}

1. Ruth grant. Physical therapy of the cervical \& thoracic spine. Churchill Livingstone, Elsevier, USA, 2002.

2. James Potter Field. Carl De Rosa mechanical neck pain, 1995.

3. Karel lewit. Manipulative therapy in rehabilitation of locomotor system, 1999.

4. Caroline Joy Co Pt. Nerve mobilization of the upper extremity. 2010;p. 56.

5. David S, Butler B Phty, Grad Dip. Mobilization of the nervous system, 1991

6. Shacklock MO. Central pain mechanisms: A new horizon in manual therapy. Aust J Physiother. 1999;45(2):83-92.

7. George Omer, Morton Spinner. Management of peripheral nerve problems: Selected laboratory studies with potential clinical application. Instr Course Lect. 1984;33:528-530.

8. Harriet Wittink, Theresa Hoskins Michel. Chronic pain management for physical therapists. $2^{\text {nd }}$ edn, Butterworth Heinemann, Elsevier, New York, USA, 2002.

9. Jackson $\mathrm{C}$ Tan. Practical manual of physical medicine and rehabilitation. $2^{\text {nd }}$ edn, 2006;pp. 858.

10. William E Prentice. Therapeuticmodalities in sports medicine, 1999.

11. Robert J Nee, David Butler. Management of peripheral neuropathic pain: Integrating neurobiology, neurodynamics, and clinical evidence. Physical Therapy in Sport. 2006;7(2):110-111.

12. Ian Macnab, John McCulloch. Neck ache \& shoulder pain. Lippincott Williams \& Wilkins, Philadelphia, USA, 1994;pp. 318-319.

13. Van der Heide B, Allison GT, Zusman M. Pain and muscular responses to a neural tissue provocation test in the upper limb. Man Ther. 2001;6(3):154-162.

14. Ellis RF, Hing WA. Neural mobilization: A systematic review of randomized controlled trails with an analysis of therapeutic efficacy. $J$ Man Manip Ther. 2008;16(1):8-22.

15. Shacklock MO. The clinical application of central pain mechanisms in manual therapy. Aust J of Physiother. 1999;45(3):215-221.

16. Brunker, Karim Khan, Peter Brunkner. Clinical sports medicine. $4^{\text {th }}$ edn, 2012 .

17. Gregory S Kolt, Lynn snyder-Mackles. Physical therapies in sport and exercise. Churchill Livingstone, Elsevier, New York, USA, 2007.

18. Darlene Hertling. Management of common musculoskeletal disorders. Lippincott Williams \& wilkins, Philadelphia, USA, 2006.

19. Joel A Delisa, Burce M Gans, Nicholas E Walsh. Physical medicine and rehabilitation: principles and practice. 2005;1:302.

20. Ramani PS. Text book of cervical spondylosis, 2004.

21. Kenneth L Knight, David O Draper. Therapeutic modalities: the art and the science, 2007.

22. Paul D Hooper. Physical therapies in sports and exercise Physical modalities.

23. Alain - Yvan Belanger. Evidence- based guide to therapeutic physical agents.

24. Sheila Kitchen, Sarach Bozin. Electrotherapy: evidence- based practice 2002;1: 299. 